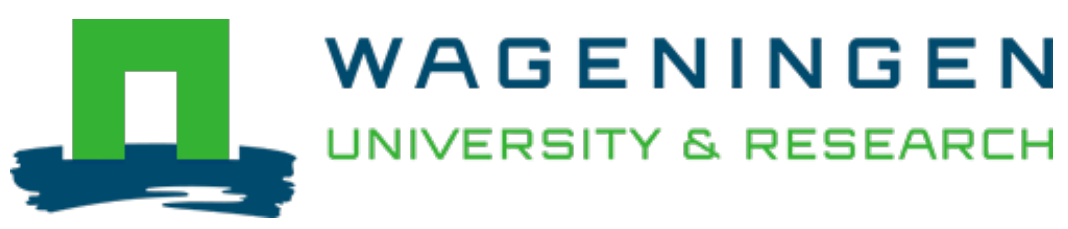

\title{
Quantifying the Contribution to Virulence of Phytophthora infestans Effectors in Potato
}

\author{
Solanum tuberosum \\ Andriani, Aviv; Wouters, Doret; Wolters, Pieter J.; Vleeshouwers, Vivianne G.A.A. \\ https://doi.org/10.1007/978-1-0716-1609-3 14
}

This publication is made publicly available in the institutional repository of Wageningen University and Research, under the terms of article $25 \mathrm{fa}$ of the Dutch Copyright Act, also known as the Amendment Taverne. This has been done with explicit consent by the author.

Article 25 fa states that the author of a short scientific work funded either wholly or partially by Dutch public funds is entitled to make that work publicly available for no consideration following a reasonable period of time after the work was first published, provided that clear reference is made to the source of the first publication of the work.

This publication is distributed under The Association of Universities in the Netherlands (VSNU) 'Article $25 \mathrm{fa}$ implementation' project. In this project research outputs of researchers employed by Dutch Universities that comply with the legal requirements of Article $25 \mathrm{fa}$ of the Dutch Copyright Act are distributed online and free of cost or other barriers in institutional repositories. Research outputs are distributed six months after their first online publication in the original published version and with proper attribution to the source of the original publication.

You are permitted to download and use the publication for personal purposes. All rights remain with the author(s) and / or copyright owner(s) of this work. Any use of the publication or parts of it other than authorised under article $25 \mathrm{fa}$ of the Dutch Copyright act is prohibited. Wageningen University \& Research and the author(s) of this publication shall not be held responsible or liable for any damages resulting from your (re)use of this publication.

For questions regarding the public availability of this publication please contact openscience.library@wur.nl 


\title{
Chapter 14
}

\section{Quantifying the Contribution to Virulence of Phytophthora infestans Effectors in Potato}

\author{
Aviv Andriani, Doret Wouters, Pieter J. Wolters, and \\ Vivianne G. A. A. Vleeshouwers
}

\begin{abstract}
Late blight in potato, caused by the oomycete Phytophthora infestans, is a devastating disease that significantly impacts potato production. For a proper understanding of disease development, it is important to understand the interaction between plant and pathogen at a molecular level. Like other pathogens, P. infestans secretes effector molecules, which can be recognized by receptors in the plant and trigger immunity. In addition, effectors from $P$. infestans have been identified to enhance disease development. Here, we describe an assay to investigate the role of effectors in virulence of $P$. infestans on potato. We combine agroinfiltration to transiently express effectors in potato with detached leaf assays to monitor disease development. This protocol makes it possible to conveniently quantify the effect of individual effectors on virulence of $P$. infestans. The identification of effectors with an important role in late blight development can help to design better strategies to control the disease.
\end{abstract}

Key words Phytophthora infestans, Late blight, Effectors, Avr genes, Agroinfiltration, Disease test, Detached leaf assay

1 Introduction

Late blight, caused by the oomycete Phytophthora infestans, is a devastating disease of potato. The disease led to the great famine in Ireland from 1845 to 1849 , causing a significant decline in the Irish population due to starvation and many Irish immigrating to other parts of the world. Late blight remains an important and remerging threat to global potato production today $[1,2]$.

A detailed understanding of the interaction between the pathogen and the host plant is important for breeding for resistance to the disease [3]. Host susceptibility and pathogen virulence can be studied using different methods. Susceptibility can, for example, be evaluated under natural conditions by performing field trials. This will make sure that resistance is studied in a relevant context. However, disease development may vary largely because of 
environmental conditions and field trials are costly and labor intensive $[4,5]$. Moreover, tight regulations are in place when genetically modified organisms (GMOs) are involved in the experiment [6]. As an alternative, disease tests can be performed in greenhouses or climate chambers under much more stable conditions [7]. This will ensure reproducibility and allows for performing experiments with GMOs under contained conditions [6]; however, it does require relatively expensive greenhouse facilities. A widely used and more high-throughput method for testing large numbers of plants and pathogen isolates is the detached leaf assay $[4,8]$. Using this somewhat artificial system compared to testing in the field or in the greenhouse, $P$. infestans infection can be studied under standardized laboratory conditions.

During infection, pathogens secrete effectors, molecules that manipulate host cell structure and function [9]. As effectors are encoded by a pathogen genome but exert their function in another organism, in this case the host plant, they are beautiful examples of genes with an extended phenotype [10]. On the one hand, effectors facilitate infection, for example by evading recognition by the plant immune system. However, effectors can have dual roles, as they can be recognized by immune receptors from host or nonhost plants. Such recognition usually leads to a strong defense reaction called hypersensitive response (HR). This strong cell death reaction is believed to restrict pathogen growth to the site of infection and can result in immunity of the plant. HR has been used as a readout in an approach called effectoromics, where germplasm collections are screened with effectors to detect genotypes with receptors that recognize the effector [11]. The effectoromics approach can help to accelerate the subsequent mapping and cloning of $R$ genes and other types of immune receptors $[3,12]$.

Effector molecules are central to understanding the antagonistic interplay between pathogens and their host plants. Most known effectors of $P$. infestans have traditionally been named based on their avirulence (Avr) activity on host plants with matching resistance $(\mathrm{R})$ genes $[3,13]$, but in more recent years, also studies for virulence activity are underway. High-throughput screens with transiently expressed GFP-tagged effectors followed by inoculation with $P$. infestans have been reported to lead to enhanced colonization in the model plant Nicotiana benthamiana [14]. For some of these effectors, their role in virulence has been characterized in great detail. For example, AVR2 is exploiting cross talk between brassinosteroid signaling and innate immunity. AVR2 interacts with the kelch-repeat-containing phosphatase, BSLl, which is involved in growth-promoting brassinosteroid pathway of potato. Transient expression of $A v r 2$ compromises immune responses to elicitins of P. infestans in N. benthamiana and stable overexpression of Avr2 in transgenic potato leads to reduced infection rates [15-17]. AVR3a in turn is manipulating the host ubiquitin proteasome system, by 
stabilizing the ubiquitin E3 ligase CMPG1. AVR3a also suppresses elicitin-mediated cell death responses and is believed to promote virulence during the early biotrophic infection phase [1820]. P. infestans is a rapidly evolving pathogen and genes encoding $A v r$ genes are typically quickly modified or lost to avoid detection by the plant immune system [21]. We anticipate that it is important to understand the role of effectors in pathogen virulence, and by targeting effectors with an important (or essential) role in virulence, it might be possible to obtain a more durable resistance $[3,13]$.

We have developed an assay to investigate and quantify the role of individual effectors in virulence of $P$. infestans on potato. In this protocol, effectors are transiently expressed in potato leaves through Agrobacterium tumefaciens-mediated transient transformation (ATTA) and P. infestans is inoculated on the leaf panels where the effectors are produced. By comparing the effect of different effectors with negative controls, the role of individual effectors on virulence of $P$. infestans can be assessed. A better understanding of the role of effectors of $P$. infestans in late blight development might enable us to design better strategies to control the disease.

\section{Materials}

\subsection{Potato \\ Propagation}

\subsection{Phytophthora infestans Spore Production}

All materials can be prepared and stored at room temperature, except when otherwise indicated. All solutions can be prepared with double-demineralized water, except when otherwise indicated. All antibiotics should be stored at $-20{ }^{\circ} \mathrm{C}$. The appropriate rules for handling GMOs and GMO waste should be followed.

1. MS20 medium: Dissolve $4.45 \mathrm{~g}$ Murashige-Skoog (MS) salts (including vitamins) and $20 \mathrm{~g}$ sucrose in $900 \mathrm{~mL}$ of doubledemineralized water $\left(\mathrm{ddH}_{2} \mathrm{O}\right)$. Then adjust the $\mathrm{pH}$ to 5.8 using $\mathrm{KOH}$ and complete the volume to $1 \mathrm{~L}$. Add $8 \mathrm{~g}$ micro agar and autoclave for $15 \mathrm{~min}$ at $121^{\circ} \mathrm{C}$.

2. Greenhouse: $8 \times 8 \times 8 \mathrm{~cm}$ pots and sterilized soil.

1. Rye agar medium: Soak $60 \mathrm{~g}$ rye grain for $36 \mathrm{~h}$ in distilled water. Separate the grains and supernatant, and keep both fractions. Macerate the swollen grain fraction, extract at $50{ }^{\circ} \mathrm{C}$ in $200 \mathrm{ML}$ ddH ${ }_{2} \mathrm{O}$, and filter. Add the supernatant into the filtrate, and make up to a final volume of $1 \mathrm{~L}$ with $\mathrm{ddH}_{2} \mathrm{O}$. Add $15 \mathrm{~g} / \mathrm{L}$ agar and $20 \mathrm{~g} / \mathrm{L}$ sucrose and autoclave for $15 \mathrm{~min}$ at $121^{\circ} \mathrm{C}$ [22]. Pour into Petri dishes for culturing Phytophthora isolates.

2. Ice-cold water. 


\subsection{Agroinfiltration}

2.4 Detached Leaf Assay
3. $50 \mathrm{~mL}$ tubes.

4. Plate spreader.

5. Hemocytometer.

1. Agrobacterium tumefaciens isolate AGLI $[23,24]$.

2. LB (Luria Bertani) broth: $10 \mathrm{~g}$ tryptone, $5 \mathrm{~g}$ yeast extract, and

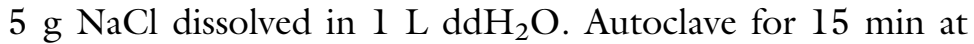
$121^{\circ} \mathrm{C}$.

3. $200 \mathrm{mM}$ acetosyringone (4-hydroxy-3,5-dimethoxyacetophenone) stock solution: $0.393 \mathrm{~g}$ acetosyringone dissolved in $10 \mathrm{~mL}$ dimethyl sulfoxide (DMSO), filter-sterilized.

4. 1 M 2-( $N$-morpholino)-ethane sulfonic acid (MES) stock solu-

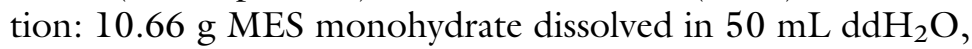
set the $\mathrm{pH}$ to 5.6 using $\mathrm{KOH}$ and filter sterilize ( see Note $\mathbf{1}$ ).

5. Yeast extract broth (YEB): $5 \mathrm{~g}$ beef extract, $5 \mathrm{~g}$ bacteriological peptone, $5 \mathrm{~g} / \mathrm{L}$ sucrose, $1 \mathrm{~g} / \mathrm{L}$ yeast extract, $0.48 \mathrm{~g} / \mathrm{L}$ $\mathrm{MgSO}_{4} \cdot 7 \mathrm{H}_{2} \mathrm{O}$ dissolved in $1 \mathrm{LddH} \mathrm{H}_{2} \mathrm{O}$. Autoclave for $15 \mathrm{~min}$ at $121^{\circ} \mathrm{C}$.

6. MMA (MS-MES-acetosyringone) buffer: $20 \mathrm{~g}$ sucrose, $5 \mathrm{~g}$ MS20 salts without vitamins, and 1.95 g MES dissolved in $900 \mathrm{~mL}$ of $\mathrm{ddH}_{2} \mathrm{O}$, set the $\mathrm{pH}$ to 5.6 using $\mathrm{HCl}$ or $\mathrm{KOH}$ and add $\mathrm{ddH}_{2} \mathrm{O}$ to obtain a final volume of $1 \mathrm{~L}$. Add $\mathrm{l} \mathrm{mL} / \mathrm{L}$ $200 \mathrm{mM}$ acetosyringone (see Note 2 ).

7. Antibiotics stock solutions ( $1,000 \times$ concentrated $): 50 \mathrm{mg} / \mathrm{mL}$ kanamycin, $50 \mathrm{mg} / \mathrm{mL}$ spectinomycin, and $50 \mathrm{mg} / \mathrm{mL}$ carbenicillin in $\mathrm{ddH}_{2} \mathrm{O}$ and filter sterilize, $50 \mathrm{mg} / \mathrm{mL}$ chloramphenicol in ethanol.

8. Plant expression vector that bears the effectors, and the empty vector negative control [25] (see Note 3).

1. Plastic trays.

2. Laboratory filter paper $(0.13 \mathrm{~mm} \times 47 \mathrm{~cm} \times 57 \mathrm{~cm})$.

3. Floral foam.

4. Toothpicks.

5. Clear plastic bags.

6. Laundry clips or tape.

\section{Methods}

Open all autoclaved materials and perform all methods inside a down-flow/cross-flow cabinet, unless indicated differently. Follow GMO regulations carefully when performing agroinfiltration. The overview of the protocol is shown in Fig. 1. 


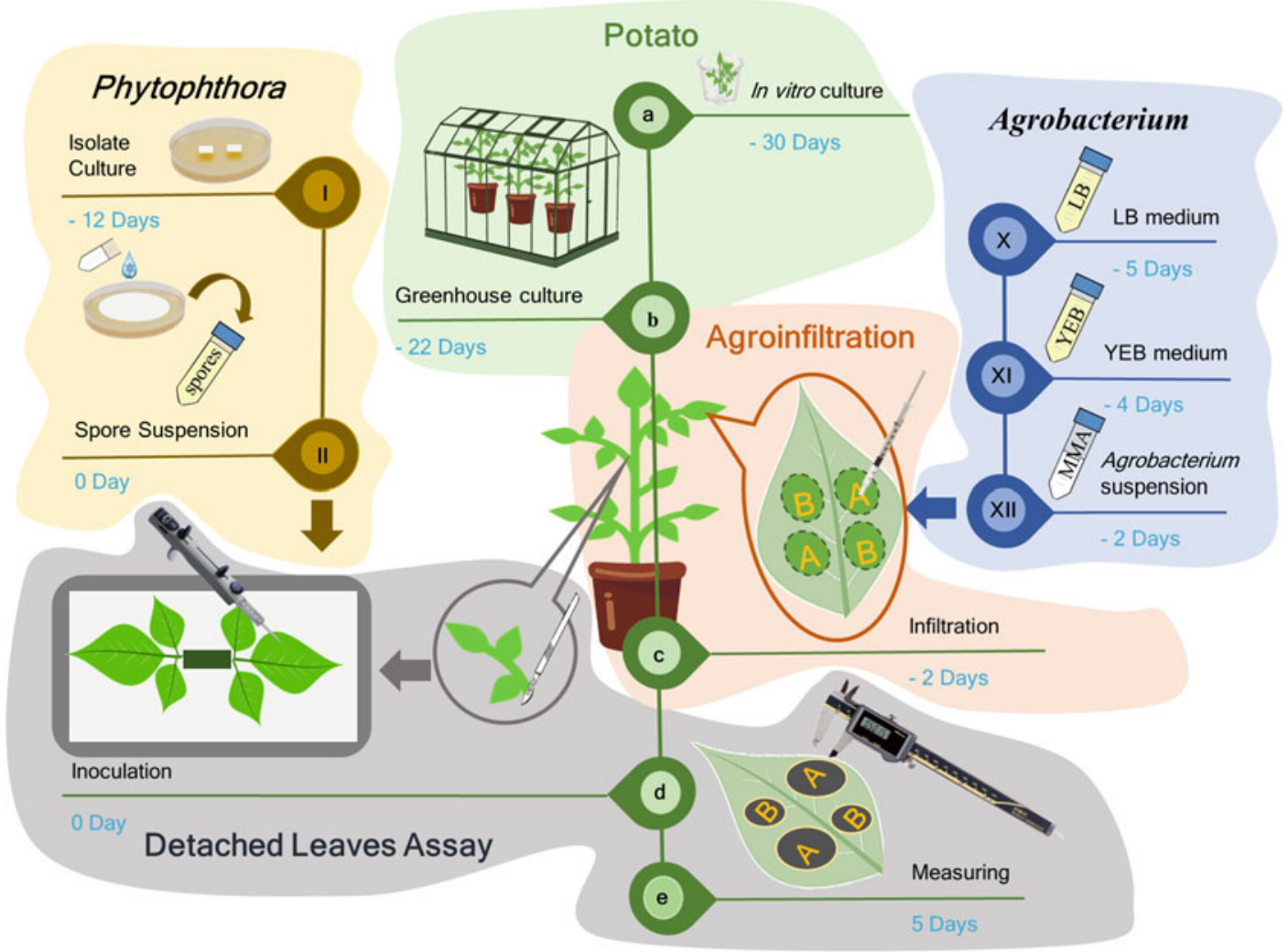

Fig. 1 Schematic overview of the protocol to investigate the effect of individual effector expression on virulence of Phytophthora infestans on potato. (a) Propagation of potato plants in vitro. (b) Growing plants in greenhouse. (c) Agroinfiltrated potato leaves. (d) Detached leaf assay. (e) Measuring lesion sizes of $P$. infestans. (I) Propagation of $P$. infestans on rye medium. (II) Preparation of spore suspension of P. infestans. (X) Growth of Agrobacterium tumefaciens containing the gene of interest construct in LB medium. (XI) Culturing $A$. tumefaciens in YEB medium. (XII) Preparation of $A$. tumefaciens suspension in MMA medium

\subsection{Potato Propagation}

1. Propagate shoots of in vitro plantlets on MS20 medium in sterile containers containing MS20 medium [26, 27].

2. Incubate shoots in a climate chamber at $18^{\circ} \mathrm{C}$ with a $16 \mathrm{~h} / 8 \mathrm{~h}$ day/night regime, for around 2 weeks until plantlets are well rooted.

3. Transplant the rooted in vitro plants into $8 \times 8 \times 8 \mathrm{~cm}$ pots containing sterile soil in a GMO-regulated greenhouse compartment for 3 weeks, at $18-22{ }^{\circ} \mathrm{C}$ with natural light complemented with artificial light under a $16 \mathrm{~h} / 8 \mathrm{~h}$ day/night regime. Apply water and fertilizer according to normal practice and use biological pest control (see Note 4). 


\subsection{Phytophthora infestans Spore Production and Preparation of Spore Suspension}

\subsubsection{Spore Production}

\subsubsection{Preparation} of Spore Suspension (the following steps do not need to be carried out under sterile conditions) (See Note 6)

\subsection{Agroinfiltration}

1. Culture the P. infestans isolates from glycerol stocks on fresh rye agar medium, and incubate at $18{ }^{\circ} \mathrm{C}$ in the dark for 14-21 days, as a starter plate for spore production.

2. Transfer agar plugs $(\sim 1 \times 1 \mathrm{~cm})$ with mycelium from the starter plate to a Petri dish containing fresh rye agar medium, and seal the lid with parafilm.

3. Incubate at $18{ }^{\circ} \mathrm{C}$ in the dark for $10-14$ days prior to inoculation (see Note 5 ).

1. Add $5 \mathrm{~mL}$ ice-cold water to a plate containing well-grown mycelium of $P$. infestans isolates (10-14 days old).

2. Rub the mycelium gently using a plate spreader.

3. Pour the sporangium suspension into a $50 \mathrm{~mL}$ tube and incubate at $4{ }^{\circ} \mathrm{C}$ for $\mathrm{l}-3 \mathrm{~h}$ to release zoospores.

4. Adjust the zoospore concentration to 50,000 spores $/ \mathrm{mL}$ using a hemocytometer. Zoospore counting method: pipet $20 \mu \mathrm{L}$ zoospore suspension and apply to the hemocytometer. Count spores under a microscope using a $10 \times 10$ magnification and calculate the average number of spores (see Note 7).

1. Prepare a tube with $5 \mathrm{~mL} \mathrm{LB}$ medium supplemented with $5 \mu \mathrm{L}$ of the appropriate antibiotics.

2. Inoculate LB with $20 \mu \mathrm{L}$ glycerol stock (see Note 8) of the Agrobacterium strain containing the expression vector for the effector of interest and the empty vector ( see Note 9).

3 . Incubate the culture on a shaking incubator at $28{ }^{\circ} \mathrm{C}$ and $200 \mathrm{rpm}$ for 1-2 days to grow a starter culture.

4. Prepare a $50 \mathrm{~mL}$ tube with $20 \mathrm{~mL}$ YEB medium complemented with $200 \mu \mathrm{L}$ of 1 M MES buffer, $2 \mu \mathrm{L}$ of $200 \mathrm{mM}$ acetosyringone stock solution, and $20 \mu \mathrm{L}$ of the appropriate antibiotics. Add $300 \mu \mathrm{L}$ of the starter culture. Incubate the culture on a shaking incubator at $28{ }^{\circ} \mathrm{C}$ with $200 \mathrm{rpm}$ for $24 \mathrm{~h}$ until the $\mathrm{OD}_{600}$ reaches about 1.0.

5. Collect the Agrobacterium cells by centrifuging the culture at $3,000 \times g$ for $10 \mathrm{~min}$.

6. Discard the supernatant, gently resuspend the pellet with MMA buffer (see Note 2), and adjust the $\mathrm{OD}_{600}$ to $0.2-0.3$.

7. Incubate the Agrobacterium suspension at room temperature for 1 to maximum $6 \mathrm{~h}$ prior to infiltration.

8. Infiltrate potato leaves on the abaxial side ( see Note 10) using a $1 \mathrm{~mL}$ syringe without needle.

9. Agroinfiltrate (see Note 11) two leaf panels with Agrobacterium containing the appropriate expression vector and two leaf panels with Agrobacterium containing the empty vector. To 


\subsection{Detached Leaf Assay}

3.4.1 Preparation of Leaves

\subsubsection{Inoculation}

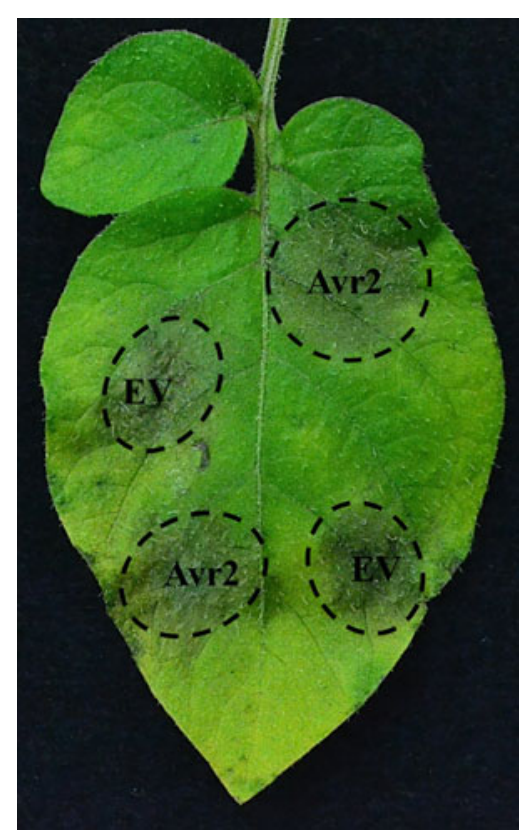

Fig. 2 Lesions from Phytophthora infestans isolate Dinteloord at 5 days postinoculation (dpi) on leaf panels treated with Agrobacterium expressing Avr2 and EV (empty vector) in potato cultivar Bintje

exclude position effects, each treatment (effector and empty vector) should occur left and right from the vein as well as at top or bottom position (Figs. 1 and 2).

10. Use at least three fully expanded leaves from at least three plants of 2-3 weeks old (see Note 12).

1. Collect three agroinfiltrated leaves at $48 \mathrm{~h}$ post-agroinfiltration, using a sharp knife or scissors. Keep the leaves moist by putting them on wet paper inside a plastic bag.

2. Soak floral foam in tap water for 15-20 min until well saturated. Cut into blocks of approximately $5 \times 5 \times 5 \mathrm{~cm}$.

3. Place two layers of wet filter paper in plastic trays.

4. Cut the end of the petiole of the leaves using a sharp knife. In each block of floral foam, insert two leaves on opposite sides of the block, with the abaxial side facing upward. Place the floral foam containing the leaves into the tray. Each tray can usually accommodate three blocks of floral foam (see Note 13 and Fig. 3).

1. Inoculate the abaxial side of the leaves at the center of each agroinfiltrated leaf panel with $10 \mu \mathrm{L}$ suspension of $P$. infestans spores ( see Note 14). 


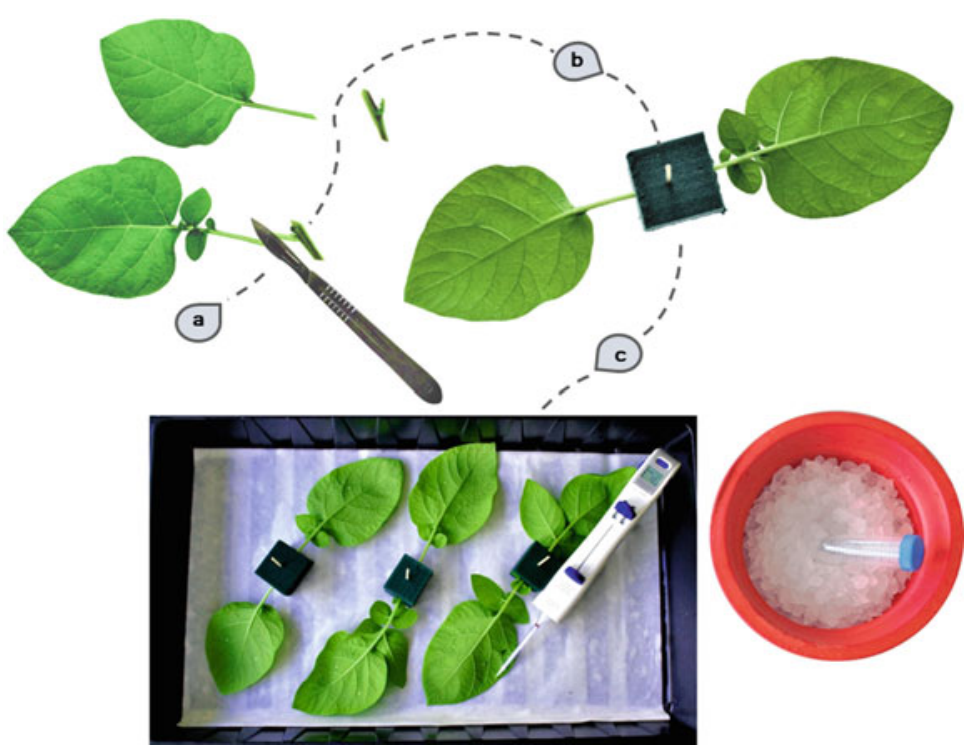

Fig. 3 Leaf preparation. (a) Potato leaves are collected, and petioles are cut with a sharp knife. (b) The leaves are inserted into blocks of wetted floral foam, and (c) placed in a tray with wetted filter paper. The leaves are now ready for inoculation with zoospore suspensions (kept on ice)

2. Put the trays in transparent plastic bags and close the bags using laundry clips or tape to keep relative humidity ( $\mathrm{RH})$ high.

3. Incubate the trays in a climate chamber at $18{ }^{\circ} \mathrm{C}$ and $\mathrm{RH}>95 \%$ under long-day conditions ( $16 \mathrm{~h} / 8 \mathrm{~h}$ day $/$ night regime) under fluorescent light tubes for 4-6 days (see Note 15).

1. Determine the lesion sizes using a digital caliper (see Note 16).

\section{Notes}

1. To reach the final concentration in $50 \mathrm{~mL}$, first add $10.66 \mathrm{~g}$ MES monohydrate to $25 \mathrm{~mL}$ of $\mathrm{ddH}_{2} \mathrm{O}$, add $5 \mathrm{~mL} \mathrm{KOH}$, and adjust $\mathrm{pH}$ to 5.6. Bring to a final volume of $50 \mathrm{~mL}$ with dd $\mathrm{H}_{2} \mathrm{O}$.

2. MMA buffer should be prepared fresh on the same day as the agroinfiltration. Add the acetosyringone after adjusting the $\mathrm{pH}$.

3. We use pK7WG2 as plant expression vector; source and details can be found at https://gatewayvectors.vib.be/collection/ pk7wg2 [28].

4. To avoid the risk that pesticides/fungicides can interfere with $P$. infestans infection, biological pest control is used. We use Thripex (contains predatory mites (Neoseiulus cucumeris)) to 
control common greenhouse pests such as thrips and mites; source and details can be found at https://www.koppert.nl.

5. The duration of the incubation depends on the $P$. infestans isolate. For instance, P. infestans isolate Dinteloord will cover the entire Petri dish with white fluffy mycelium in about 10 days, whereas isolate Katshaar will need 14 days to cover the plate.

6. The zoospore suspension is freshly made on the same day as the detached leaf assay. Zoospores that are actively moving are preferred, as we found that these are more virulent.

7. Take sporangiospores into account when counting zoospores; they can be counted as zoospores.

8. The glycerol stocks are stored at $-20{ }^{\circ} \mathrm{C}$. Either defrost them on ice and take $20 \mu \mathrm{L}$ or keep them in liquid nitrogen and take a small scoop from the frozen glycerol stock.

9. Always include a culture of Agrobacterium with empty vector as a negative control.

10. Choose young, healthy, and fully expanded leaves for agroinfiltration. These are usually leaves $2-4$ (counted from the top) at the middle part of the plant. If the plants have more than one leaflet, choose the main leaflet.

11. Use eye protection during the agroinfiltration. To avoid cross contamination, always change gloves or sterilize using $70 \%$ ethanol when infiltrating different effector treatments.

12. Avoid watering the plants after agroinfiltration, especially using a water sprayer, to avoid cross contamination.

13. The number of floral foam blocks per tray depends on the size of the leaves. For medium-sized leaves, such as those from potato cultivar Bintje, two leaves fit per floral foam block, and six leaves fit in a tray.

14. One agroinfiltrated leaf panel can accommodate a $10 \mu \mathrm{L}$ droplet of spore suspension from a single isolate (use different leaves for different isolates).

15. The length of the incubation is dependent on the aggressiveness of the inoculated $P$. infestans isolates. The more aggressive, the shorter the incubation time. For instance, the aggressive $P$. infestans isolate Dinteloord takes 5 days to cover the entire leaf of potato cultivar Bintje and the lesions from different inoculated spots will start to merge. In comparison, $P$. infestans isolate Katshaar will take 6 days on this cultivar.

16. The development of $P$. infestans is determined by measuring the lesion sizes before the lesions will start overlapping (see Note 14). 


\section{References}

1. Haverkort AJ, Struik PC, Visser RGF, Jacobsen E (2009) Applied biotechnology to combat late blight in potato caused by Phytophthora Infestans. Potato Res 52(3):249-264

2. Fry W, Birch P, Judelson H et al (2015) Five reasons to consider Phytophthora infestans a reemerging pathogen. Phytopathology 105 (7):966-981

3. Vleeshouwers VG, Raffaele S, Vossen JH et al (2011) Understanding and exploiting late blight resistance in the age of effectors. Annu Rev Phytopathol 49:507-531

4. Vleeshouwers VGAA, van Dooijeweert W, Paul Keizer LC et al (1999) A laboratory assay for Phytophthora infestans resistance in various Solanum species reflects the field situation. Eur J Plant Pathol 105(3):241-250

5. Douches DS, Kirk WW, Bertram MA et al (2002) Foliar and tuber assessment of late blight (Phytophthora infestans (Mont.) de Bary) reaction in cultivated potato (Solanum tuberosum L.). Potato Res 45(2):215-224

6. Sensi A, Brandenberg O, Gosh K, Sonnino A (2011) Biosafety resource. FAO, Rome

7. Dorrance AE, Inglis DA (1997) Assessment of greenhouse and laboratory screening methods for evaluating potato foliage for resistance to late blight. Plant Dis 81(10):1206-1213

8. Goth RW, Keane J (1997) A detached-leaf method to evaluate late blight resistance in potato and tomato. Am Potato J 74 (5):347-352

9. Kamoun S (2006) A catalogue of the effector secretome of plant pathogenic oomycetes. Annu Rev Phytopathol 44:41-60

10. Dawkins R (1983) The extended phenotype: the long reach of the gene. Oxford University Press, Oxford

11. Vleeshouwers VG, Rietman H, Krenek P et al (2008) Effector genomics accelerates discovery and functional profiling of potato disease resistance and phytophthora infestans avirulence genes. PLoS One 3(8):e2875

12. Du J, Verzaux E, Chaparro-Garcia A et al (2015) Elicitin recognition confers enhanced resistance to Phytophthora infestans in potato. Nat Plants 1(4):15034

13. Birch PR, Armstrong M, Bos J et al (2009) Towards understanding the virulence functions of RXLR effectors of the oomycete plant pathogen Phytophthora infestans. J Exp Bot 60 (4):1133-1140

14. Wang S, McLellan H, Bukharova Tet al (2019) Phytophthora infestans RXLR effectors act in concert at diverse subcellular locations to enhance host colonization. J Exp Bot 70 (1):343-356

15. Gilroy EM, Breen S, Whisson SC et al (2011) Presence/absence, differential expression and sequence polymorphisms between PiAVR2 and PiAVR2-like in Phytophthora infestans determine virulence on R2 plants. New Phytol 191(3):763-776

16. Turnbull D, Yang L, Naqvi S et al (2017) RXLR effector AVR2 up-regulates a Brassinosteroid-responsive bHLH transcription factor to suppress immunity. Plant Physiol 174(1):356-369

17. Saunders DG, Breen S, Win J et al (2012) Host protein BSLl associates with Phytophthora infestans RXLR effector AVR2 and the Solanum demissum immune receptor $\mathrm{R} 2$ to mediate disease resistance. Plant Cell 24(8):3420-3434

18. Armstrong MR, Whisson SC, Pritchard L et al (2005) An ancestral oomycete locus contains late blight avirulence gene Avr3a, encoding a protein that is recognized in the host cytoplasm. Proc Natl Acad Sci U S A 21:7766-7771

19. Bos JI, Armstrong MR, Gilroy EM et al (2010) Phytophthora infestans effector AVR3a is essential for virulence and manipulates plant immunity by stabilizing host E3 ligase CMPG1. Proc Natl Acad Sci U S A 107(21):9909-9914

20. Bos JI, Kanneganti TD, Young C et al (2006) The C-terminal half of Phytophthora infestans RXLR effector AVR3a is sufficient to trigger R3a-mediated hypersensitivity and suppress INFl-induced cell death in Nicotiana benthamiana. Plant J 48(2):165-176

21. Haas BJ, Kamoun S, Zody MC et al (2009) Genome sequence and analysis of the Irish potato famine pathogen Phytophthora infestans. Nature 461(7262):393-398

22. Caten CE, Jinks JL (1968) Spontaneous variability of single isolates of Phytophthora infestans I. Cultural variation. Can J Bot 46:329-347

23. Lazo GR, Stein PA, Ludwig RA (1991) A DNA transformation-competent Arabidopsis genomic library in Agrobacterium. Biotechnology (NY) 9(10):963-967

24. Du J, Rietman H, Vleeshouwers VG (2014) Agroinfiltration and PVX agroinfection in potato and Nicotiana benthamiana. J Vis Exp 83:e50971

25. Domazakis E, Lin X, Aguilera-Galvez C et al (2017) Effectoromics-based identification of cell surface receptors in potato. In: Shan L, He P (eds) Plant pattern recognition receptors: 
methods and protocols. Springer, New York, pp 337-353

26. Hussey G, Stacey NJ (1981) In vitro propagation of potato (Solanum tuberosum L.). Ann Bot 48(6):787-796

27. Murashige T, Skoog F (2006) A revised medium for rapid growth and bio assays with tobacco tissue cultures. Physiol Plant $15: 473-497$

28. Karimi M, Inze D, Depicker A (2002) GATEWAY vectors for Agrobacterium-mediated plant transformation. Trends Plant Sci 7 (5):193-195 